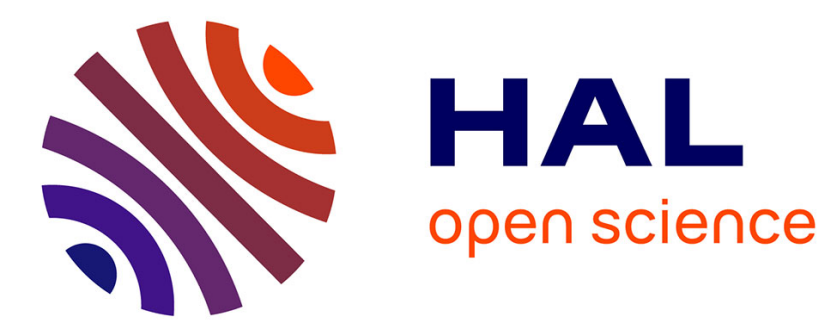

\title{
Life-time history of suicide attempts and coronary artery disease in a community-dwelling elderly population.
}

\author{
Sylvaine Artero, Bernard Astruc, Philippe Courtet, Karen A. Ritchie
}

\section{To cite this version:}

Sylvaine Artero, Bernard Astruc, Philippe Courtet, Karen A. Ritchie. Life-time history of suicide attempts and coronary artery disease in a community-dwelling elderly population.. International Journal of Geriatric Psychiatry, 2006, 21, pp.108-112. 10.1002/gps.1429 . inserm-00069435

\section{HAL Id: inserm-00069435 https://www.hal.inserm.fr/inserm-00069435}

Submitted on 28 Oct 2008

HAL is a multi-disciplinary open access archive for the deposit and dissemination of scientific research documents, whether they are published or not. The documents may come from teaching and research institutions in France or abroad, or from public or private research centers.
L'archive ouverte pluridisciplinaire HAL, est destinée au dépôt et à la diffusion de documents scientifiques de niveau recherche, publiés ou non, émanant des établissements d'enseignement et de recherche français ou étrangers, des laboratoires publics ou privés. 
Life-time history of suicide attempts and coronary artery disease in a communitydwelling elderly population

\author{
S. Artero ${ }^{1 *}$, B. Astruc ${ }^{2}$, P. Courtet ${ }^{2}$, K. Ritchie ${ }^{1}$.
}

${ }^{1}$ Inserm, E361, 34093 Montpellier, France; Univ Montpellier 1, Montpellier, F-34000 France

${ }^{2}$ Department of Psychological Medicine and Psychiatry, Lapeyronie Hospital, CHU Montpellier, France

${ }^{*}$ Correspondence to Dr Sylvaine Artero

Inserm E361 : Epidemiology of Nervous System Pathologies

Hopital La Colombière, pav 42

39 avenue Flahault, BP 34493 ,

34093 Montpellier Cedex 5, France.

Tel: 4996145 68; Fax: 499614579

E-mail: artero@montp.inserm.fr

Contract/Grant: Grant from Novartis and financial assistance from the Regional government of Languedoc-Roussillon 


\begin{abstract}
Background: Numerous studies have observed a strong relationship between coronary artery disease (CAD) and psychiatric disorder; notably depression, anxiety and panic attacks. No study has, however, explored the question of whether persons suffering from CAD might also be at high risk of suicide attempts.

Objective: The aim of the present study is to examine the relationship between CAD within a general population cohort and life-time history of psychiatric disorder and suicidal behaviour.

Method: A representative sample of 1843 non-institutionalized persons over 65 , drawn at random from the electoral roll, was given a standardized neurological and psychiatric examination based on DSM IV criteria. The clinical examination also included an electrocardiogram (ECG) and a questionnaire relating to life-time medical history. Cardiac events were validated by the general practitioner.
\end{abstract}

Results: Within this general population sample the prevalence of suicide attempts $3.9 \%$. A significant positive association was observed between life-time prevalence of CAD and suicide attempts $(p<0.04)$. Suicide attempts were associated with major depression $(p<0.001)$ co-morbid anxiety and depression $(p<0.001)$ but not anxiety alone $(p=0.16)$. A logistic regression analysis showed that the relationship between suicide attempts and CAD persists after adjustment for depression and anxiety. Conclusion : CAD is associated with suicidal behaviour independently of depression, however, longitudinal studies are required to clarify the direction of causality and to integrate genetic, biological, environmental and psychological factors into an aetiological model. 
Key Words: suicide attempt, coronary artery disease, depression, anxiety 


\section{Introduction}

Numerous studies have demonstrated an association between coronary artery disease (CAD) and psychiatric disorder, notably depression, anxiety, and panic attacks. The prevalence of major depression in patients with CAD is about 3-fold higher than in community samples, ranging from $16 \%$ to $23 \%$ (Schleifer et al., 1989; Frasure-Smith et al., 1993; Gonzales et al., 1996). Prospective epidemiological studies have demonstrated a significant relationship between depression and the incidence of cardiac events in healthy populations (Aromaa et al., 1994; Ford et al., 1998). A recent systematic review (Wulsin et al., 2003) suggests that depressive symptoms constitute a significant and independent risk for the onset of CAD, a risk (1.64) that is greater than the risk conferred by passive smoking (1.25) but less than the risk conferred by active smoking (2.5). Depression appears to be both a risk factor and a consequence of cardiovascular pathology. CAD has also been linked to anxiety disorders. Three large-scale community-based studies have reported a significant relationship between anxiety and death due to cardiac pathology in men (Haines et al., 1987; Kawachi et al., 1994). A study by Weissman (1990) has further demonstrated a link between CAD and panic attacks.

While CAD appears to be linked with psychiatric disorder, the biological mechanisms underlying these associations remains unclear. It is also not known whether this vulnerability to psychiatric disorder, in particular depression, also gives rise to higher rates of suicidal behaviour in persons with CAD, given that suicidal behaviour is also common in other chronic diseases such as cancer, stroke and COPD (Druss and 
Pincus, 2000; Bronnum-Hansen $\mathrm{H}$ et al, 2001). France has not only a high rate of CAD along with other western countries, it also has a high suicide rate, especially for men reaching 148 per 100,000 compared to 24 per 100,000 for women over 85 .

Suicide rates in the elderly in France are amongst the highest in Europe, reaching 0.06\% over age 85 (Institut National de la Santé et de la Recherche Médicale, 1999). Suicidal behaviour has multiple causes and the identification of risk factors is an important first step for the development of public health prevention programs. In this study we examine the hypothesis that persons with CAD may be an at-risk group.

\section{Subjects and Methods}

The present study is part of the ESPRIT Project (Enquête de Santé Psychologique Risques, Incidence et Traitement), a prospective general population study of life-time psychiatric disorder in persons over 65 in the Montpellier region of the South of France. The methodology of the study is described in detail elsewhere (Ritchie et al. 2004). A random sample of 1863 community-dwelling persons over 65 was drawn from the 15 electoral rolls of the Montpellier district between March 1999 and February 2001. Subjects were examined in a clinical research centre established for the purposes of the study at the Gui de Chauliac Neurology Hospital in Montpellier. Subjects unable to come to the centre were examined in their homes. Of the subjects initially drawn at random, $27.3 \%$ did not participate (of these $3.3 \%$ did not participate due to severe disability). Refusers were replaced by another subject drawn at random from the same electoral division such that each division is equally represented. Subjects refusing were slightly older and more likely to live alone than non-refusers. 


\section{Clinical examination}

The clinical examination consisted of a standardized neurological examination and an ECG by a neurologist, and administration of the Mini International Neuropsychiatric Interview (MINI) (French version 5.00) validated in the general population setting by Lecrubier et al. (1997) which provides DSM IV (American Psychiatric Association, 1994) diagnoses for the suicidal behaviours, the suicidal ideation and the principle Axis I psychiatric disorders.

The MINI was administered by trained interviewers (nurses and psychologists) and positive cases were reviewed by a clinical panel of three psychiatrists.

\section{Standardized health questionnaire}

The project interviewers administered a general health questionnaire covering history of medical disorders, treatment and surgical procedures. Information was also obtained on medication, family medical history and tobacco use. With regard to CAD the questionnaire focused on history of angina pectoris, myocardial infarction (MI) and coronary surgery (dilatation and by-pass). Information obtained from subjects was validated by the general practitioner. Informed written consent was obtained from all subjects and ethical approval for the study was obtained from a regional ethics committee. 


\section{Data Analysis}

Logistical regression modelling procedure (entry mode) was carried out to examine the association between life-time history of suicide attempts (dependant variable) and CAD using the SPSS (Statistical Package for Social Science) program, version 12.

\section{Results}

The mean age of the sample of 1863 subjects is 73 years $(S D=6) ; 58.5 \%$ women and $41.5 \%$ men. All subjects completed the medical examination and the psychiatric interview. The life-time prevalence of suicide attempts in the sample is $3.7 \%(n=69)$ and suicidal risk is estimated at $9.8 \%$. (Table 1).

Table 1 here

$79.7 \%$ of the suicide attempts were carried out by women $(p<0.001)$, the divorce or separation rate in attempters was $53.6 \%$ compared to $28 \%$ in non-attempters. $71 \%$ of attempters reported having at least one previous episode of major depression (compared to $29 \%$ in non-attempters) and $26.1 \%$ report an episode of generalized anxiety (compared to $10.2 \%$ in non-attempters) $(p<0.001) .75 .4 \%$ of attempters have received treatment for major depression and $67.7 \%$ were hospitalized for treatment. Attempters also consumed significantly more psychotropic medication than nonattempters $(18.8 \%$ and $6.1 \%$ respectively) $(p<0.00)$. No significant difference was found with regard to tobacco use. With regard to CAD, significantly higher rates of angina pectoris $(p<0.001)$ and coronary surgery $(p<0.05)$ were observed in 
attempters, but not of myocardial infarction. However, this may be due to the very low rates of life-time infarction in this sample (Table 2).

Table 2 here

A logistical regression model was used to examine the association between life-time history of suicide attempts and CAD (the CAD variable combined angina, MI and coronary surgery). The model was adjusted for age, sex, education level, and a psychiatric disorder variable broken into four categories of neither depression or anxiety (the reference category), anxiety without depression, depression without anxiety, and anxiety/depression co-morbidity (Table 3).

Table 3 here

Suicide attempts were found to be associated with depression (beta=1.87; $p<0.00$ ), co-morbid anxiety and depression (beta=2.21; $\mathrm{p}<0.00$ ) but not with anxiety alone (beta $=0.91 ; p=0.16)$. After adjustment on all variables a significant association was still found between suicide attempts and CAD (beta=0.77; $p<0.05)$.

\section{Discussion}

The results of this general population study of life-time psychiatric disorder show a strong positive association between history of suicide attempts and CAD without taking into account the chronological order of appearance of each of these pathologies. An obvious conclusion would be that this relationship is moderated by the presence of depression, which is common to both. However, while CAD subjects 
were found to have high rates of depression, and depression was also found to be related to suicide attempts, surprisingly CAD is seen to be linked to suicide attempts independently of its relationship to depression. Life-time suicide attempts are seen to be strongly linked to depression, depression with anxiety, but not with anxiety alone. A previous study conducted in Germany has also attested to the strong suicide risk associated with not only depression but also anxiety disorders when depression is also present (Bronisch et al., 1994). This risk is seen to be higher than for depression alone.

How might we incorporate these findings into a hypothetical aetiological model? There is already significant epidemiological evidence linking psychosocial factors and CAD. Psychological factors such as depression, anxiety, personality factors and character traits; chronic life stress, and social isolation contribute to the risk of CAD (Jenkins, 1982) and may predict poor treatment outcomes (Rutledge et al., 1999). Type A behavior patterns are also accepted as a coronary risk factor. Using metaanalysis techniques to examine the relationship between personality and cardiovascular disease Booth-Kewley and Friedman (1987) found considerable statistical evidence for the concept of type A personality over a 30-year period. Other researchers have found that expressed hostility, a major attribute of the type $A$ behavior pattern, is considered to be more pathogenic. Hostility is a broad psychological construct, encompassing negative orientations toward interpersonal relationships and includes such traits as anger, cynicism and mistrust. Hostility has been associated with the severity of angina and duration of heart disease (Tennant and Langeluddecke 1985), and with the severity of atherosclerosis, independently of the association between type A and CAD (Williams et al., 1980). In a review of the 
impact of emotions on CAD risk, Tennant and McLean (2001) noted that both crosssectional and prospective studies revealed an association between anger/hostility and clinical indices of CAD. An association between anger/hostility and suicidal behavior has been reported in several studies since 1975, and family history of suicidal behavior appears to be associated with greater anger (Hawton et al., 2002) and levels of aggression and impulsivity seem to be highly correlated with past suicidal behavior (Mann et al., 1999). An accumulating body of evidence suggests multiple pathophysiological mechanisms by which hostility may be link to CAD (Rozanki et al., 1999) and this may be the possible link between suicidal behavior and CAD (Suarez et al., 1999; Sloan et al., 1994; Markovitz, 1998). An alternative hypothesis is that the association between CAD and suicide attempts is not causal but that both pathologies share common genetic factors associated with vascular vulnerability which may also be modulated by high risk environments.

While this interesting finding opens up new research pathways to explore causality in late-life suicide attempters, it should also be noted that our study has a number of short-comings; this over 65 sample has excluded subjects dying at younger ages due to both suicide attempts and more severe CAD. The study is moreover, crosssectional and is therefore unable to establish the order of events and hence causality. A prospective study starting at younger ages is needed to validate and further explore this preliminary finding. Such a study should also include measures of hostility and anger in order to clarify the role of mediating psychological factors and investigate possible underlying vascular factors from early adulthood. 


\section{References}

American Psychiatric Association. 1994. Diagnostic and Statistical Manual of Mental Disorders (DSM-IV). Washington, DC: American Psychiatric Association.

Aromaa A, Raitasalo R, Reunanen A, et al. 1994. Depression and cardiovascular diseases. Acta Psychiatr Scand 377(suppl): 77-82.

Booth-Kewley S, Friedman HS. 1987. Psychological predictors of heart disease: A quantitative review. Psychol Bull 101: 343-362.

Bronisch T, Wittchen HU. 1994. Suicidal ideation and suicide attempts: comorbidity with depression, anxiety disorders, and substance abuse disorder. Eur Arch Psychiatry Clin Neurosci.244: 93-98.

Bronnum-Hansen H, Davidsen M and Thorvaldsen P. 2001. Long-term survival and causes of death after stroke. Stroke 32: 3131-2136.

Druss B, Pincus H.2000. Suicidal ideation and suicide attempts in general medical illnesses. Arch Intern Med 160: 1522-1526.

Ford DE, Mead LA, Chang PF et al. 1998. Depression is a risk factor for coronary artery disease in men. Arch Intern Med 158:1422-1426.

Frasure-Smith N, Lesperance F, Talajic M. 1993. Depression following myocardial infarction: impact on 6-month survival. JAMA 270:1819-1861. 
Gonzales MB, Snyderman TB, Colket JT, Arias RM, Jiang JW, O'Connor CM, Krishnan KR. 1996. Depression in patients with coronary artery disease. Depression 4:57-62.

Haines Ap, Imeson JD, Meade TW. 1987. Phobic anxiety and ischemic heart disease. BMJ.295: 297-299.

Hawton K, Haw C, Houston K, Townsend E. 2002. Family history of suicidal behaviour: prevalence and significance in deliberate self-harm patients. Acta Psychiatr Scand 106:387-93.

Institut National de la Santé et de la Recherche Médicale (1999) Informations sur les causes médicales de décès. Taux de mortalité par suicide en France entre 1995 et 1997. Inserm Service Commun 8, Insee (restricted access).

Jenkins C.D. 1982. Psychosocial risk factors for coronary heart disease. Acta Med Scand 660:123-136.

Kawachi I, Colditz GA, Ascherio A, Rimm EB, Giovannucci E, Stampfer MJ, Willerrt WC. 1994. Prospective study of phobic anxiety and risk of coronary heart disease in men. Circulation 89:1992-1997.

Lecrubier Y, Sheehan D, Weiller E, et al. 1997. The Mini International Neuropsychiatric Interview (MINI), a short diagnostic interview: reliability and validity according to the CIDI. European Psychiatry 12: 232-241 
Mann JJ, Waternaux C, Haas GL, Malone KW. 1999. Toward a clinical model of suicidal behaviour in psychiatric patients. Am J Psychiatry 156: 181-189.

Markovitz JH. 1998. Hostility is associated with increased platelet activation in coronary heart disease. Psychosom Med 60: 586-591.

Ritchie K, Artero S, Beluche I; et al. 2004. Prevalence of DSM-IV psychiatric disorder in the French elderly population. Br J Psychiatry 184: 147-152.

Rozanski A, Blumenthal J, Kaplan J. 1999. Impact of psychological factors on the pathogenesis of cardiovascular disease and implications for therapy. Circulation 99: 2192-2217.

Rutledge T, Linden W, Davies R.F. 1999. Psychological risk factors may moderate pharmacological treatment effects among ischemic heart disease patients. Canadian Amlodipine/Atenolol in Silent Ischemia Study (CASIS) Investigators. Psychosom Med 61: 834-841.

Schleifer SJ, Macari-Hinson MM, Coyle DA, Slater WR, Kahn M, Gorlin R, Zucker HD. 1989. The nature and course of depression following myocardial infarction. Arch Intern Med 149:1785-1789.

Sloan R, Shapiro P, Bagiella E, Steinman R, Gorman J. 1994. Cardiac autonomic control and hostility in healthy subjects. Am J Cardiol 74: 298-300. 
Suarez EC, Kuhn CM, Schanberg SM, Williams RB Jr, Zimmermann EA. 1998.

Neuroendocrine, cardiovascular, and emotional responses of hostile men: the role of interpersonal challenge. Psychosom Med 60:78-88.

Tennant C.C, Langeluddecke P.M. 1985. Psychological correlates of coronary heart disease. Psychol Med 15:581-588.

Tennant C.C, McLean L. The impact of emotions on coronary heart disease risk. 2001. J Cardiovasc Risk 8:175-183.

Weissman MM, Markowitz JS, Ouellette R, Greenwald S, Kahn J. 1990. Panic disorders and cardiovascular/cerebrovascular problems: result from a community survey. Am J Psychiatry.147: 1504-1508.

Williams R.B, Haney T.L, Lee K.L, Kong Y, Blumenthal J.A, Whalen R.E. Type A behavior, hostility, and coronary atherosclerosis. 1980. Psychosom Med 42: 539-549.

Wulsin LR and Singal BM. 2003. Do depressive symptoms increase the risk for the onset of coronary disease? A systematic quantitative review. Psychosom Med 65:201-210. 
Acknowledgements : The ESPRIT Project is financed by an unconditional research grant from Novartis and financial assistance from the Regional government of Languedoc-Roussillon. The authors wish to thank the project interviewers Isabelle Beluche, Martine Dieusy, Lucette Para, Lucienne Brissaud; Francine Jourdan for data entry and Dr Sophie Garcia for discussions. 
Table 1. Demographic, cardiovascular and psychopathological characteristics of the population

Characteristic $(\mathrm{N}=1863)$

Age years, mean (SD)

$72.84(5.37)$

Sexe, women \% (n)

$58.5(1090)$

Low school education \% (N)

$26(586)$

Ever used tabacco \% (N)

$42.1(785)$

Angina pectoris \% $(\mathrm{N})$

$8.1(179)$

Myocardial infarct \% (N)

$3.7(69)$

Antecedents of coronary surgery

(dilatation or bridging)

$8.3(154)$

Lifetime major depressive episode \% (N)

$26.5(494)$

Single episode

$15(281)$

Recurrent episode

$9.4(176)$

Life time generalized anxiety \% (N)

$10.8(201)$

Suicide attempt

$3.7(69)$

Suicidal ideation

$9.8(182)$ 
Table 2. Association of lifetime history of suicide attempt with cardiovascular risk factor, lifetime psychiatric history and psychotropic medication

\section{Suicide attempt status}

Variables

Age (years)

sexe (women)

Low school education

Divorced/widowed

Ever smokers

Hypertension

(Treatment or systolic bp $>140$ or diastolic $b p>90$ )

Angina pectoris

Myocardial infarct

Antecedents of coronary surgery

(dilatation or bridging)

Life time generalized anxiety

Life time history of major depression

Current major depression

Any psychotropic medication

\begin{tabular}{|c|c|c|}
\hline $\begin{array}{l}\text { Suicide attempt } \\
\qquad(\mathrm{n}=69)\end{array}$ & $\begin{array}{c}\text { No suicide attem } p t \\
(n=1834)\end{array}$ & \\
\hline \multicolumn{2}{|c|}{ mean (SD) } & $\mathrm{p} \dagger$ \\
\hline $72.62(5.09)$ & $72.85(5.39)$ & 0.73 \\
\hline \multicolumn{2}{|c|}{ percent distribution $(n)$} & $\mathrm{p}+$ \\
\hline $79.7(55)$ & $57.9(1029)$ & 0.00 \\
\hline $20.3(14)$ & $24.3(424)$ & 0.48 \\
\hline $53.6(37)$ & $28(495)$ & 0.00 \\
\hline $37.7(26)$ & $42.2(748)$ & 0.26 \\
\hline $57.1(1014)$ & $62.3(43)$ & 0.23 \\
\hline $15.2(10)$ & $6.1(105)$ & 0.00 \\
\hline $1.5(1)$ & $3.8(68)$ & 0.31 \\
\hline $14.5(10)$ & $8(143)$ & 0.05 \\
\hline $26.1(18)$ & $10.2(181)$ & 0.00 \\
\hline $71(49)$ & $29(20)$ & 0.00 \\
\hline $11.6(8)$ & $2.8(50)$ & 0.00 \\
\hline $18.8(13)$ & $6.1(108)$ & 0.00 \\
\hline
\end{tabular}


Table 3. Logistic regression analysis: lifetime association between suicide attempt and coronary artery disease

\begin{tabular}{lcc}
\multicolumn{1}{c}{ Variables } & Beta & Significance \\
\hline Coronary artery disease & 0.77 & 0.04 \\
No depression, no anxiety (ref) & & 0.00 \\
Anxiety without depression (1) & 0.91 & 0.16 \\
Depression without anxiety (2) & 1.87 & 0.00 \\
Depression and anxiety (3) & 2.21 & 0.00 \\
Education (low level) & -0.20 & 0.50 \\
Sexe (female) & 0.73 & 0.02 \\
Age & & 0.71 \\
\hline
\end{tabular}

